\title{
Wind tunnel analysis of artificial substrates used in active living walls for indoor environment conditioning in Mediterranean buildings
}

\author{
A. Franco ${ }^{a}$, R. Fernández-Cañero ${ }^{a}$, L. Pérez-Urrestarazu ${ }^{a}$, D.L. Valera ${ }^{\text {b,* }}$ \\ ${ }^{a}$ University of Seville, ETSIA Ctra, de Utrera km 1, 41013 Sevilla, Spain \\ ${ }^{\mathrm{b}}$ University of Almeria, Campus de Excelencia Internacional Agroalimentario ceiA3, Ctra, de Sacramento s/n, 04120 Almería, Spain
}

\section{A R T I C L E I N F O}

\section{Article history:}

Received 8 October 2011

Received in revised form

29 November 2011

Accepted 3 December 2011

\section{Keywords:}

Active living wall

Substrates

Wind tunnel

Evaporative cooling

Pressure drop

Saturation efficiency

\begin{abstract}
A B S T R A C T
In this paper, a low-speed wind tunnel was used for experimental analysis of water volume retained, pressure drop, saturation efficiency and water consumption for three types of synthetic substrates used in active living walls: polyester (PR), polyurethane (PU) and polyamide-polypropylene (PA-PP) The substrates were of a similar thickness and were tested for different water and air flows. The water retained increases with higher water flow. The pressure drop increases with the presence of vegetation and when air speed and water flow is higher. Cooling efficiency is enhanced with vegetation and low air speed. Specific consumption of water is greater with vegetation at higher air speeds. Therefore, low air (between 0.25 and $0.5 \mathrm{~m} \mathrm{~s}^{-1}$ ) and water flows are recommended to ensure a homogeneous wetting of the substrate surface. PA-PP has the greatest pressure drop of the three, but also presents the best saturation efficiency, with an average water retention capacity and less specific consumption. PU offers the least resistance to air flow, with an intermediate efficiency level and high water consumption and water retention capacity. PR presents the worst saturation efficiency, a medium level of pressure drop and high water consumption.
\end{abstract}

(c) 2011 Elsevier Ltd. All rights reserved.

\section{Introduction}

Given the current energy crisis and emphasis on issues such as sustainability, efficiency and environmental concerns, governments and businesses alike are striving to reduce energy consumption in buildings and to use their facilities more efficiently.

In Spain the residential and services sectors represent $67.5 \%$ of the total consumption of electricity, $42.1 \%$ of which is consumed in buildings [1]. Cooling and heating systems are responsible for $59 \%$ of this demand [2], mainly as a result of the high energy requirements of air-conditioning equipment used to maintain a comfortable living/working environment and to guarantee indoor air quality. Indeed, these sectors have greater opportunities to moderate energy consumption without reducing the level of comfort and well-being of people [3]. In addition, current high levels of energy consumption are not sustainable because of the high costs and foreseeable exhaustion of energy sources. In addition, they also imply major environmental consequences for the planet, increasing emissions of greenhouse gases to the atmosphere, which contributes to global warming.

\footnotetext{
* Corresponding author. Tel.: +34 950015546; fax: +34 950015491.

E-mail address: dvalera@ual.es (D.L. Valera).
}

In the future, average temperatures are expected to increase, so cooling is becoming a primary and energy demanding problem. For example, probabilistic projections on climate change for the United Kingdom [4] suggest an expected increase in demand for cooling in buildings. Hence, the employment of additional evaporative cooling systems will be even more necessary to reduce the thermal load of the building.

In this context, the use of urban greening systems alone or in combination with conventional air-conditioning systems in buildings may, in addition to providing a high ornamental and environmental value, contribute to reduce energy consumption.

The urban greening movement is a response to the loss of green spaces in cities and buildings through the use of many technologies contributing to the goal of urban sustainability. It aims to transform buildings and urban spaces into biotopes, providing many energy and environmental benefits [5]. Living walls on facades and inside buildings and the installation of green roofs are the most innovative urban greening techniques. They provide powerful tools for bioclimatic design and sustainable architecture.

Vertical greening can be defined as the design and construction of gardens on vertical surfaces. Pérez et al. [6] recently classified the many systems currently available, indicating their different levels of complexity and technification. The simplest are based on the use of climbing plants for the landscaping of facades, but more complex 
systems, known as living walls or green walls, have recently appeared. In these the plants grow directly on the vertical surface rather than from the base [7]. Some are based on hydroponic cropping systems, such as the living walls designed by the French botanist Patrick Blanc [8]. They use a support structure providing an inorganic substrate into which the plants are inserted, and they can be classified as passive or active systems (Fig. 1). Active systems are designed with ventilators which force an air flow through the substrate and plant rooting system. Therefore the air is filtered and purified in a process known as biofiltration [9] which also acts as a natural cooling system. These systems can be completed with a closed circuit irrigation installation, thus improving water use efficiency.

These facilities are undoubtedly of great beauty, they can be installed both inside and outside of the buildings, and they have numerous energy benefits, such as the increase in the thermal insulation of the building envelope [10,11], energy savings for ventilation requirements (ventilation needs are reduced due to the improvement of biofiltrated air) and temperature reduction [12-14]. Other environmental benefits include the improvement of air quality, with the fixation of $\mathrm{CO}_{2}$ and VOCs [15], oxygen production, improvement of the working environment, reduction of stress and absenteeism [16] and enhancing acoustic comfort [17]. They also increase biodiversity in the urban environment [18] and contribute to the reduction of the urban heat island effect $[19,20]$.

When these systems are installed in the interior of buildings the effects on the conditions of indoor temperature and humidity are more remarkable [21,22].

A new system of active living wall has been developed and patented in the Higher Technical School of Agronomic Engineering in Seville (Spain). As well as maintaining all the benefits of passive living walls, it also enhances their role as an ecological system for climate conditioning and air biofiltration. This living wall can operate independently (as in the present work) or combined with the building's system of air-conditioning and ventilation of (Fig. 2).

The system operates based on the evaporation of water from the substrate of the active living wall, producing a significant decrease in temperature and an increase in the humidity of the air. The change of phase from liquid to vapor requires energy extracted from the hot air from the outside or from warmer indoor air. The result is a cooling effect and an increase in the air moisture content. In thermodynamics the process is termed adiabatic, and the enthalpy remains virtually constant [23].

The cooling capacity of these systems may be affected in high humidity locations, such as the Mediterranean coastal areas; but bearing in mind the great variation in humidity throughout the day, these devices prove effective in the central hours, when the ambient temperature is high and the relative humidity lower. In addition, due to their capacity as biofilters [24,25], the rate of renewal of air is lower and therefore less energy consumption is required due to ventilation.

Given that the evaporation of the water occurs in the substrate of the living wall, it is interesting to evaluate the performance of different growing media or substrates. They allow air and water to flow through them, favoring the growth of vegetation and root development. In addition, they act as an interchange of energy and mass for air-conditioning.

The present work, therefore, aims to assess the suitability of three different substrates for use in active living walls. Operating equations will be obtained using a low-speed wind tunnel in laboratory conditions. Different air and water flows and presence of vegetation are tested in order to assess their influence on pressure drop, air saturation efficiency and the volume of water evaporated and retained.

\section{Material and methods}

\subsection{Low-speed wind tunnel}

To determine the performance of different substrates for active living walls, a low-speed open-circuit wind tunnel with a circular cross-section has been used (Fig. 3). The wind tunnel was designed and constructed in the Department of Rural Engineering of the University of Almería [26], where it was modified and adapted to test evaporative pads [27]. A uniform and stable air flow was achieved (just as reported by Fang et al. [28]) under controlled conditions of temperature and humidity. By applying a regulated water flow an optimal distribution is achieved in the porous media.

For the purposes of this study, measurements of air speed and flow of water through the porous medium (substrate) are required.

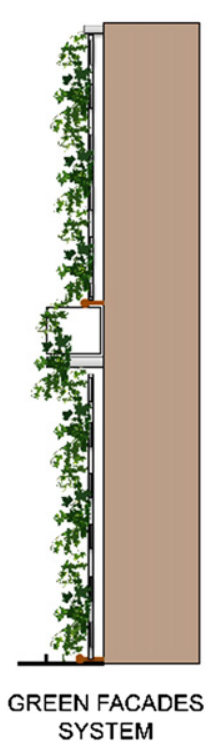

SYSTEM
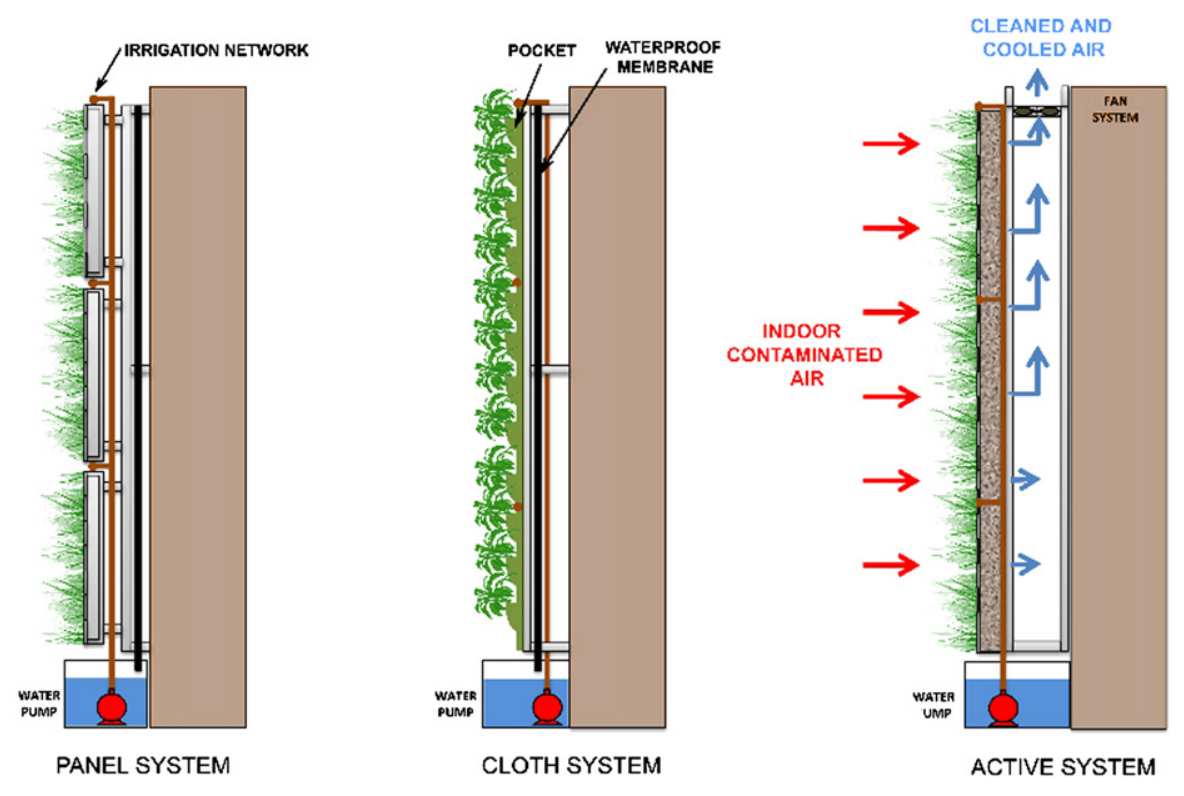

Fig. 1. Vertical greening systems. 

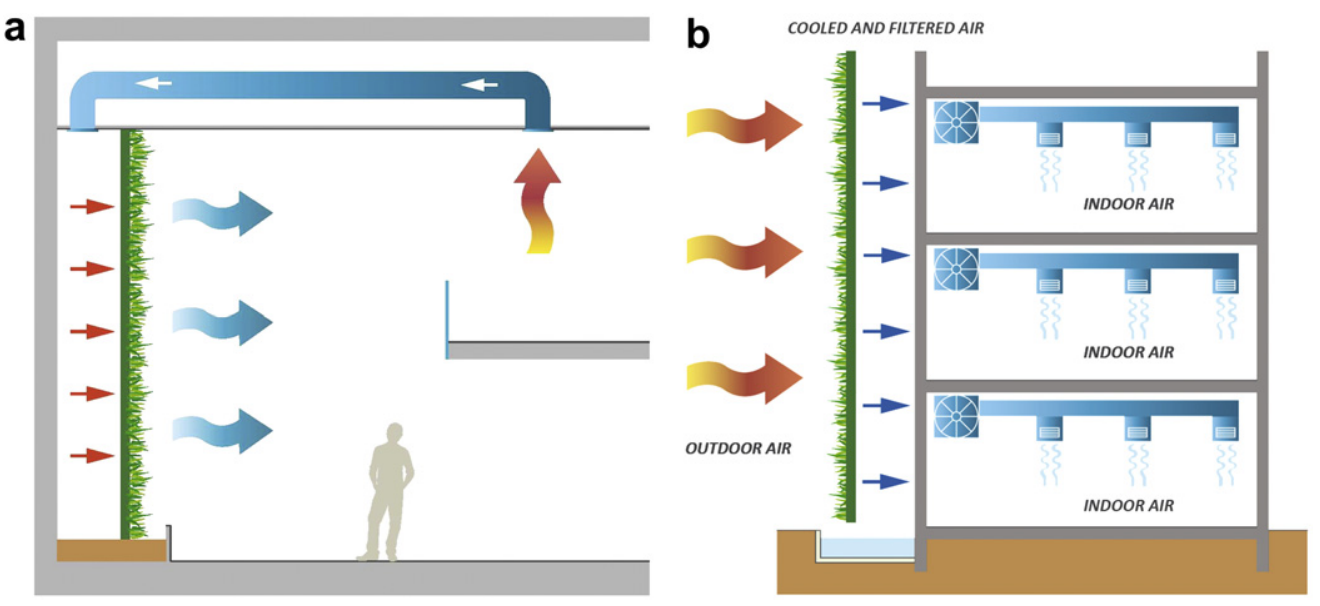

Fig. 2. Operation of active living walls: (a) Indoors; (b) Outdoors.

Other required data include the temperature and humidity of the air flow before and after crossing the substrate to determine the saturation efficiency of the substrate and the volume of evaporated water. Liao and Chiu [29] performed a similar analysis for evaporative pads made of alternative materials of PVC sponge. It is also necessary to measure the air pressure drop through the substrate using a pressure transducer connected to two pitot tubes placed before and after the pad. The volume of water retained by the substrate is measured as the difference in weight between the dry and wetted pads.

In order to carry out tests in the wind tunnel, a specific test frame was designed to incorporate the pads. This frame consisted of a galvanized metal structure with a water distribution system incorporated in the upper part. The water distribution system consisted of a $20 \mathrm{~mm}$ diameter PVC pipe with $1.5 \mathrm{~mm}$ holes $25 \mathrm{~mm}$ apart. In the lower part of the frame, there was a water collection system allowing water to drain by gravity into a tank, before being recycled by a $12 \mathrm{~V}$ axial pump. Water flow at the entrance was controlled by varying the voltage of the continuous current hydraulic pump and readings from the rotameter (flow meter), with an average range of 3-22 L per minute and an error of $\pm 4 \%$.

The volume of water retained by the substrate depending on the applied flow was averaged taking into account the variation of the weight of water in the recirculation tank using a scale system with analog outputs consisting of a load cell of $50 \mathrm{~N}$ capacity and a VMA10 signal conditioner.

Airflow was supplied by a centrifugal fan HCT-45-2T-3/AL (Sodeca S.A., Sant Quirze de Besora, Spain) with a capacity of $12,800 \mathrm{~m}^{3} \mathrm{~h}^{-1}$ and a rotational speed of $2865 \mathrm{rpm}$. A Micromaster 420 AC Inverter (Siemens España S.A., Madrid, Spain) was used to regulate the air speed in the test section, with an output frequency of $0-50 \mathrm{~Hz}$ and a set point resolution of $0-1 \mathrm{~Hz}$. The real time readings were stored on the hard disc of a personal computer via the data acquisition unit. EE70-VT32C5 (Elektronik, Engerwitzdort, Austria) air velocity and temperature transmitters were placed $950 \mathrm{~mm}$ upstream from the measurement section, equipped with a directional hot-film anemometer with a working range of $0-10 \mathrm{~m} \mathrm{~s}^{-1}$ and accuracy of $\pm 0.1 \mathrm{~m} \mathrm{~s}^{-1}$, for air velocity measurements.

The temperature and humidity of the air current were measured using six digital relative humidity/temperature sensors of the SHT75 series (Sensirion, Zurich, Switzerland) with a 9-bit digital outlet that does not require calibration and with an accuracy of $\pm 1.8 \%$ for relative humidity and of $\pm 0.3{ }^{\circ} \mathrm{C}$ for temperature. These sensors were located in groups of three, $700 \mathrm{~mm}$ upstream and downstream from the sample to be tested. They were mounted on two rods placed across the width of the test section.

The static pressure drop through the test section was measured by a differential pressure transducer SI 727 (SI-Special Instruments, Nörlingen, Germany) connected to two $4 \mathrm{~mm}$ diameter Pitot tubes (Airflow Developments Ltd., Buckinghamshire, England) located $450 \mathrm{~mm}$ upstream and downstream from the middle of the test section. The transducer measurement range was 0-200 Pa with an accuracy of $\pm 0.25 \%$ full scale (f.s.), hysteresis and reproducibility of $\pm 0.1 \%$ f.s., and temperature error of $\pm 0.025 \% /{ }^{\circ} \mathrm{C}$, and a $0-10 \mathrm{~V}$ signal output.

The signals that the sensors emitted were recorded by means of an electric circuit designed ad hoc with eight analogical inputs with a resolution of 10 bits, six digital inputs for humidity/temperature sensors and an input for three temperature probes controlled by a bus. The flow of control and data was managed by an RS232C connection to a PC.

\subsection{Substrate characterization and test procedure}

Three different synthetic and inorganic substrates (Fig. 4) have been analyzed regarding their capacity for climate conditioning. Each is made up of several layers of synthetic textile fibers sewn together forming a grid of 100 by $100 \mathrm{~mm}$. The plants are inserted through a horizontal opening into a kind of pocket formed between

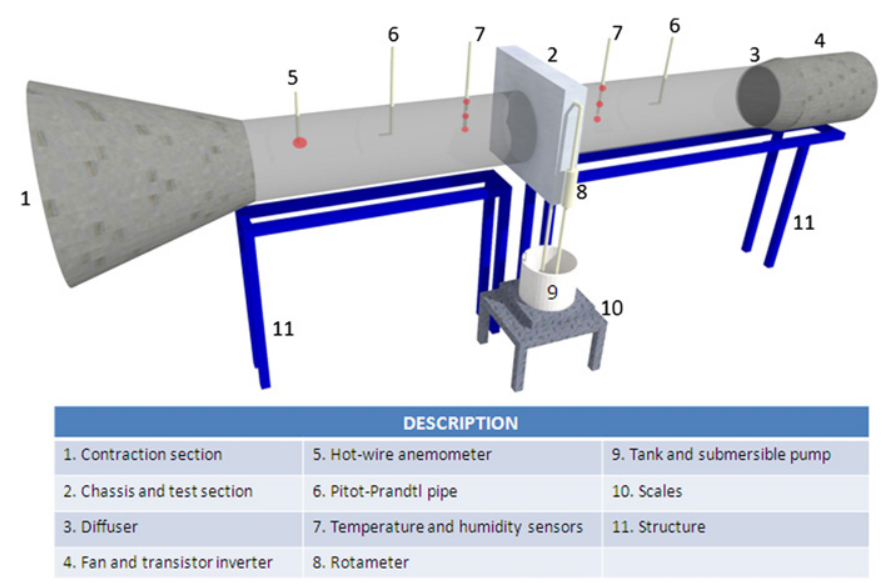

Fig. 3. Diagram of the wind tunnel with controlled water and air flow rate (not to scale). 

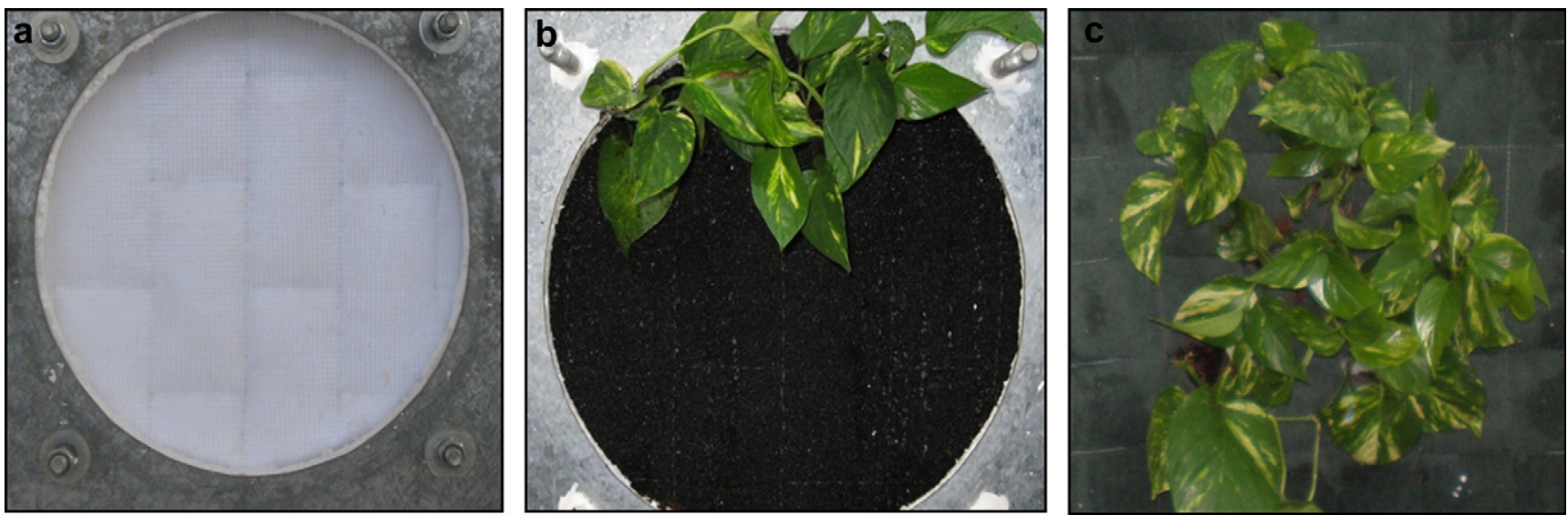

Fig. 4. Tested substrates: (a) Polyester (PR); (b) Polyurethane (PU); (c) Polyamide-Polypropylene (PA-PP).

the layers of fiber. These substrates are a porous medium that must allow plant development and enhance epiphyte growth, while also allowing air and water to flow through them.

The following substrates were tested:

- PR: Comprising three layers, the external and internal ones made of an insect mesh and a $15 \mathrm{~mm}$ polyester fiber between them.

- PU: Comprising three $5 \mathrm{~mm}$ layers of polyurethane.

- PA-PP: Comprising a $6 \mathrm{~mm}$ external layer of polyamide and a $10 \mathrm{~mm}$ interior layer of polypropylene.

Three samples of each substrate were tested $(0.6 \mathrm{~m}$ wide by $0.65 \mathrm{~m}$ high). The total thickness of all three substrates is approximately $15 \mathrm{~mm}$. The influence of vegetation in the operating parameters of the substrates was analyzed by planting Pothos (Scindapsus aureus Engl.) in 50\% of the grid of the wind tunnel test section. The leaf area index was maintained constant in the different samples and substrates. Wang and Zhang [30] also used this type of vegetation in the evaluation of an air filtration system.

The $20 \mathrm{~mm}$ PVC pipe used for wetting had $1.5 \mathrm{~mm}$ holes separated by $25 \mathrm{~mm}$, leaving four holes each grid of the substrate to obtain a homogeneous wet pattern. It was inserted between the layers of each substrate sample with the holes directed vertically downwards.

The flows of water employed expressed as volume per unit area were: 0 (dry), 615, 770, 925, 1075 and $1230 \mathrm{~L} \mathrm{~h}^{-1} \mathrm{~m}^{-2}$. Franco et al. [31] found a direct influence of water flow in the operation parameters of corrugated cellulose evaporative pads. The flow was regulated by varying the tension of the hydraulic pump with a power source and adjusting it with a rotameter, and three replications were made for each flow and substrate sample. Initially these flows were used to determine the volume of water retained by substrates without vegetation, as it is more interesting to know the substrates' water retention capacity before it is altered by the volume of peat when plants are transplanted (approximately $300 \mathrm{~cm}^{3}$ /plant). On analyzing the other operating parameters in the wind tunnel, the air stream passing through the substrate was observed to cause an undesirable drip out of water at flows of over $770 \mathrm{~L} \mathrm{~h}^{-1} \mathrm{~m}^{-2}$. Consequently, only three flow variables were tested: dry (only for the pressure drop), 615 and $770 \mathrm{~L} \mathrm{~h}^{-1} \mathrm{~m}^{-2}$.

The range of speeds of the air inlet was set between 0.05 and $1 \mathrm{~m} \mathrm{~s}^{-1}$. Higher speeds are not recommended due to problems of mechanical damage to vegetation.

The test procedure began by determining the volume of water retained by the substrate depending on the flow applied. Average values were obtained of the variation of weight in the recirculation water tank for the substrate without vegetation. As no air flow was applied and the measurement time was $10 \mathrm{~min}$ for each water flow, the water evaporated during the test was considered negligible.

Subsequently, in order to determine the remaining operating parameters, a water flow was set. After 10 min the fan was started at an initial velocity close to $0.05 \mathrm{~m} \mathrm{~s}^{-1}$, gradually incremented by $0.15 \mathrm{~m} \mathrm{~s}^{-1}$ up to $1 \mathrm{~m} \mathrm{~s}^{-1}$. After each increment, the substrate was allowed to adapt to the new conditions for a period of $5 \mathrm{~min}$. At each speed, 50 data values were taken with each sensor, with a data acquisition interval of $3 \mathrm{~s}$. Tests were repeated with vegetation in the substrates in order to compare their performance.

\subsection{Mathematical model}

Saturation efficiency $(\eta)$ is the key index used to evaluate the benefits of substrates. This is determined as the ratio between the drop in air temperature after passing through the pad and the maximum possible drop under conditions of air saturation [23]:

$\eta=\frac{T_{1}-T_{2}}{T_{1}-T_{\mathrm{wb}}}$

where $T_{1}$ is the dry temperature of the incoming air $\left({ }^{\circ} \mathrm{C}\right) ; T_{2}$ is the dry temperature of the outgoing air $\left({ }^{\circ} \mathrm{C}\right)$, and $T_{\mathrm{wb}}$ is the thermodynamic temperature of the wet-bulb at the entrance.

The value of saturation efficiency depends on the air speed through the pad, the specific surface of the pad (wet surface) and the water/air ratio.

The specific water consumption $\left(C_{\mathrm{w}}\right)$ of the pads $\left(\mathrm{kg} \mathrm{h}^{-1} \mathrm{~m}^{-2}{ }^{\circ} \mathrm{C}^{-1}\right)$ is expressed as the mass flow of evaporated water $\left(m_{\mathrm{e}}\right)$ per unit of exposed surface $(A)$ and the maximum thermal difference possible given the conditions of air entering the pad [27]

$C_{\mathrm{w}}=\frac{m_{\mathrm{e}}}{\left(T_{1}-T_{2}\right) \cdot A}$

where the mass flow of evaporated water $\left(m_{\mathrm{e}}\right)$ is obtained by applying the water vapor balance:

$m_{\mathrm{e}}=m_{\mathrm{v} 2}-m_{\mathrm{v} 1}$

$m_{\mathrm{v} 1}$ and $m_{\mathrm{v} 2}$ are the flows of vapor at the entrance and exit of the pad, respectively $\left(\mathrm{kg} \mathrm{h}^{-1}\right)$.

Dividing equation ( 3 ) by the flow of dry air $\left(m_{\mathrm{a}}\right)$ in $\mathrm{kg} \mathrm{h}^{-1}$ which is constant between the entrance and exit of the pad: 


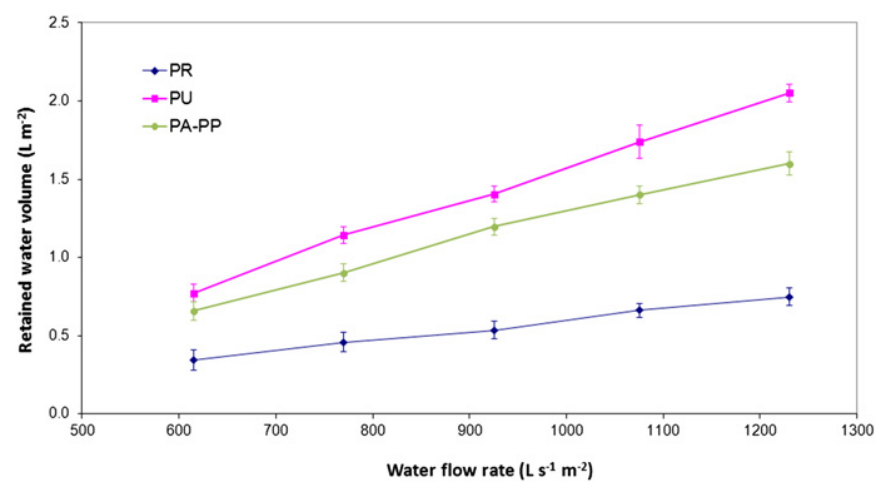

Fig. 5. Volume of water retained by surface and error based on flow unit.

$m_{\mathrm{e}}=m_{\mathrm{a}}\left(W_{2}-W_{1}\right)$

where $W_{1}$ and $W_{2}$ are the absolute humidity of the air at the entrance and exit of the pad, respectively $\left(\mathrm{kg}_{\mathrm{w}} \mathrm{kg}_{\mathrm{a}}^{-1}\right)$ and $m_{\mathrm{a}}=\rho_{\mathrm{a}} \cdot Q_{\mathrm{a}}$, in which $\rho_{\mathrm{a}}$ is the air density $\left(\mathrm{kg} \mathrm{m}^{-3}\right)$ and $Q_{\mathrm{a}}$ is the air flow through the pad $\left(\mathrm{m}^{3} \mathrm{~h}^{-1}\right)$.

Substituting expression (2) in equation (1), the pad's evaporated water depends on the air speed through it, the saturation efficiency of the pad and the air conditions on entering the pad:

$C_{\mathrm{w}}=\frac{m_{\mathrm{e}}}{\eta\left(T_{1}-T_{\mathrm{wb}}\right) A}$

The pressure loss produced by substrates for the different speeds of the air and water flow applied, both with and without vegetation, is directly obtained by the pressure difference between the input and output registered by the pressure transducer and pitot tubes.

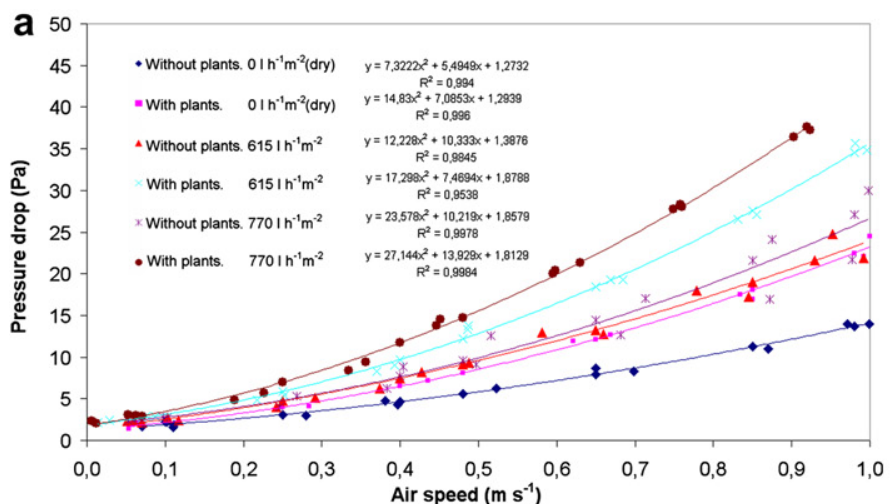

\section{Results and discussion}

\subsection{Volume of water retained by the substrates}

The results show that the volume of water retained by substrates per unit area is directly related to the flow of water applied at the top (Fig. 5). PU retains most water, 0.77 to $2.05 \mathrm{~L} \mathrm{~m}^{-2}$ (average of $1.42 \mathrm{~L} \mathrm{~m}^{-2}$, average error of $6.37 \%$ ), followed by PA-PP, 0.66 to $1.60 \mathrm{~L} \mathrm{~m}^{-2}$ (average of $1.15 \mathrm{~L} \mathrm{~m}^{-2}$, average error of $5.98 \%$ ), while PR retained between 0.34 and $0.75 \mathrm{~L} \mathrm{~m}^{-2}$ (average of $0.55 \mathrm{~L} \mathrm{~m}^{-2}$, average error of $5.60 \%$ ). These results are reasonable as $\mathrm{PR}$ is a more hydrophobe material so a higher flow of water was observed running by the surface of the substrate. PU presents more porosity which increments its ability to retain water.

\subsection{Pressure drop}

The pressure drop data of the three substrates samples, obtained in the wind tunnel at different air speeds and water flows, both with and without vegetation, are shown in Fig. 6 .

As expected, increasing the speed of air passing through the pad also increments the pressure drop. For the range of speeds between 0.25 and $1 \mathrm{~m} \mathrm{~s}^{-1}$, PA-PP presents the highest pressure drop, between $3.57 \mathrm{~Pa}$ (dry without vegetation) and $71.11 \mathrm{~Pa}$ (770 $\mathrm{L} \mathrm{h}^{-1} \mathrm{~m}^{-2}$ with vegetation), followed by PR, between $3.10 \mathrm{~Pa}$ (dry without vegetation) and $26.65 \mathrm{~Pa}\left(770 \mathrm{~L} \mathrm{~h}^{-1} \mathrm{~m}^{-2}\right.$ with vegetation). For PU this value varied between $1.78 \mathrm{~Pa}$ (dry without vegetation) and $9.23 \mathrm{~Pa}\left(770 \mathrm{~L} \mathrm{~h}^{-1} \mathrm{~m}^{-2}\right.$ with vegetation). The lower pressure drop in all substrates occurs without vegetation and in dry conditions and it increases with vegetation and a higher water flow. PU shows lower pressure drop due to its higher porosity.

The presence of vegetation increased the pressure drop, as both the root system and the leaf mass offer greater resistance to the air

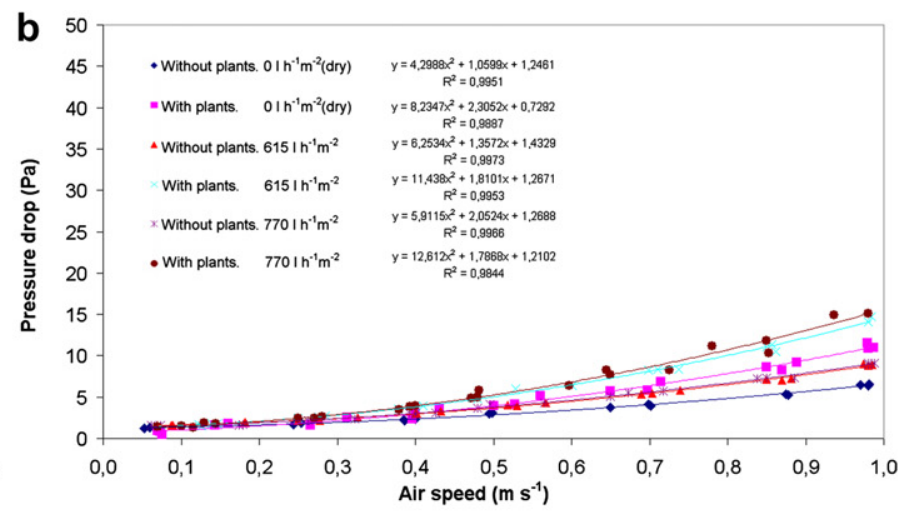

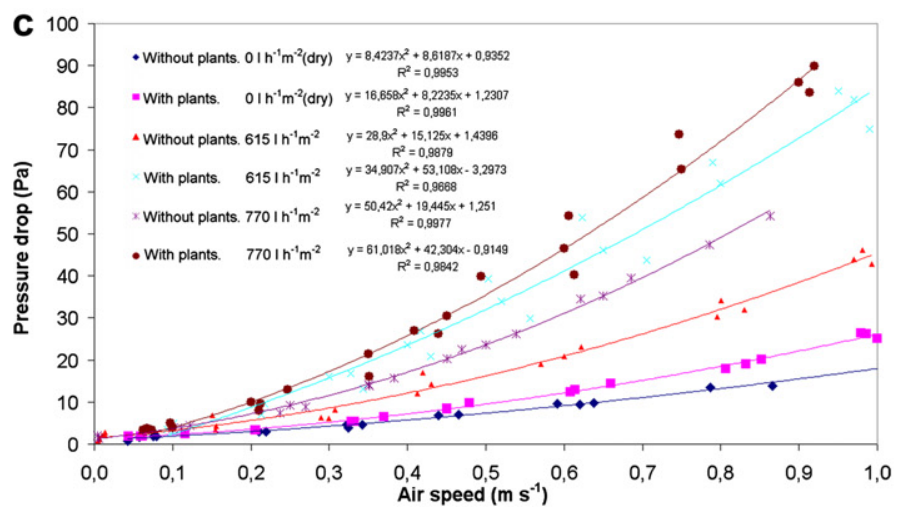

Fig. 6. Pressure drop vs. air speed: (a) Polyester (PR); (b) Polyurethane (PU); (c) Polyamide-Polypropylene (PA-PP). 

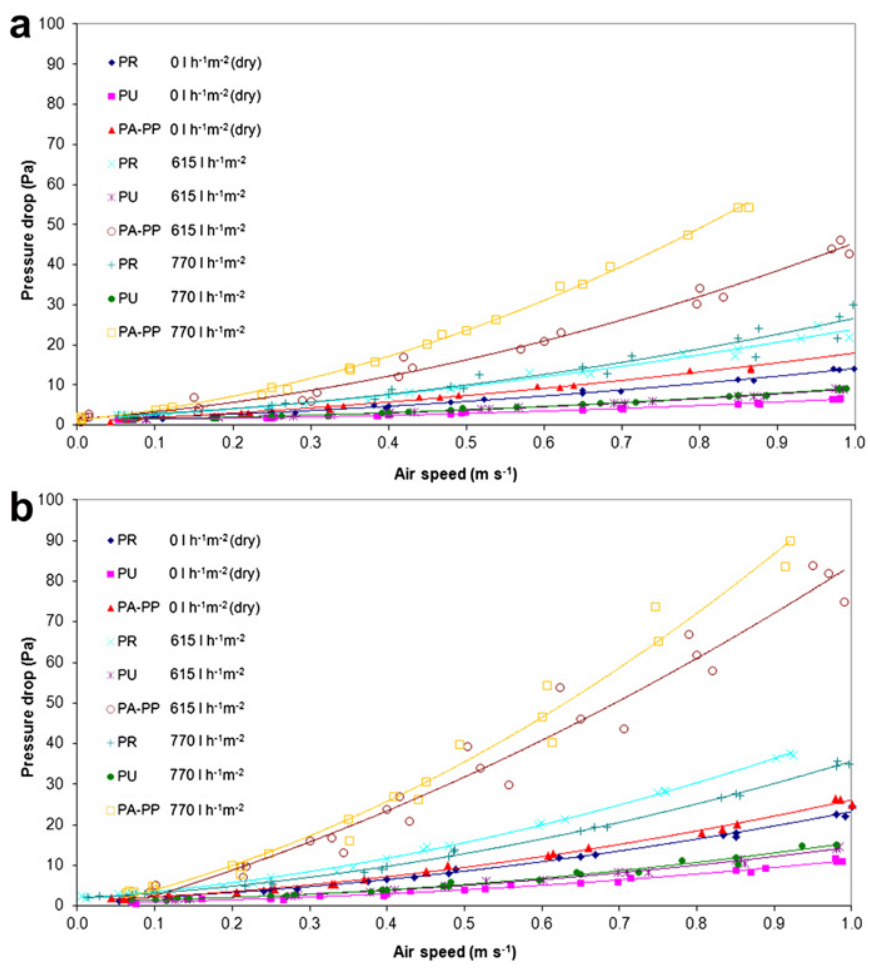

Fig. 7. Pressure drop vs. air speed: (a) without vegetation; (b) with vegetation.
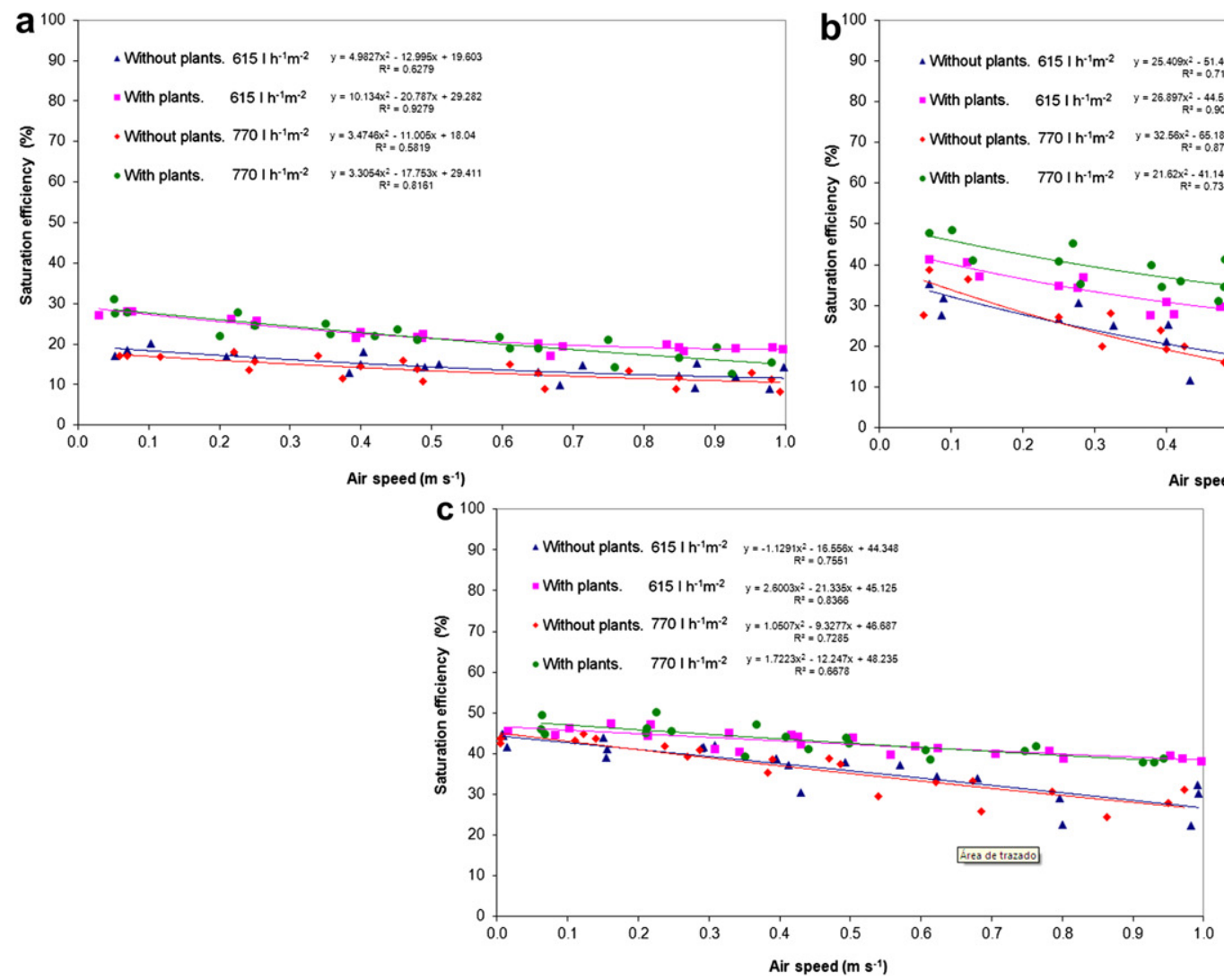

flow. This is true for all substrates under all experimental conditions. Average increases of pressure loss are $47.88 \%$ for PR, $42.59 \%$ for PU and 58.34\% for PA-PP.

For all three substrates, the higher water flow applied, the greater the pressure drop for a given air velocity. In the case of PR the pressure drop increases from $63.77 \%$ to $81.55 \%$ at 0 and $615 \mathrm{~L} \mathrm{~h}^{-1} \mathrm{~m}^{-2}$, respectively, and from $6.02 \%$ to $20.22 \%$ at 615 and $770 \mathrm{~L} \mathrm{~h}^{-1} \mathrm{~m}^{-2}$, respectively. For PU, these increases are $30.27-35.57 \%$ and 1.75-4.73\% respectively. The highest pressure drop increases were with PA-PP, 127.94-266.99\% and 14.62-46.43\% respectively. This may be due to the reduction of the panel porosity $\left(\mathrm{m}^{3} \mathrm{~m}^{-3}\right)$ as the water layer that moves over the internal surface is higher and reduces the volume of air per unit volume.

Comparing the three types of substrates with and without the presence of vegetation for different tested flows (Fig. 7), PU offers least resistance to the air flow, followed by PR, with increases of 101.54-164.23\% without vegetation and 113.24-198.96\% with vegetation. PA-PP produces the highest pressure drop with increases of $150.00-536.56 \%$ without vegetation and 136.32-539.87\% with vegetation compared to PU.

\subsection{Air saturation efficiency}

Generally speaking, at higher air speeds, the contact time between the air and water is lower, decreasing the degree of saturation of the air, and therefore lowering the saturation efficiency (Fig. 8). The same applies to the specific surface of the substrate; when it is reduced, the surface of contact between water and air is also reduced, and therefore air saturation efficiency is lower.

For the range of speeds between 0.25 and $1 \mathrm{~m} \mathrm{~s}^{-1}$, PA-PP presents the highest efficiency: between $45.45 \%\left(770 \mathrm{~L} \mathrm{~h}^{-1} \mathrm{~m}^{-2}\right.$ with vegetation) and $26.66 \%\left(615 \mathrm{~L} \mathrm{~h}^{-1} \mathrm{~m}^{-2}\right.$ without vegetation),

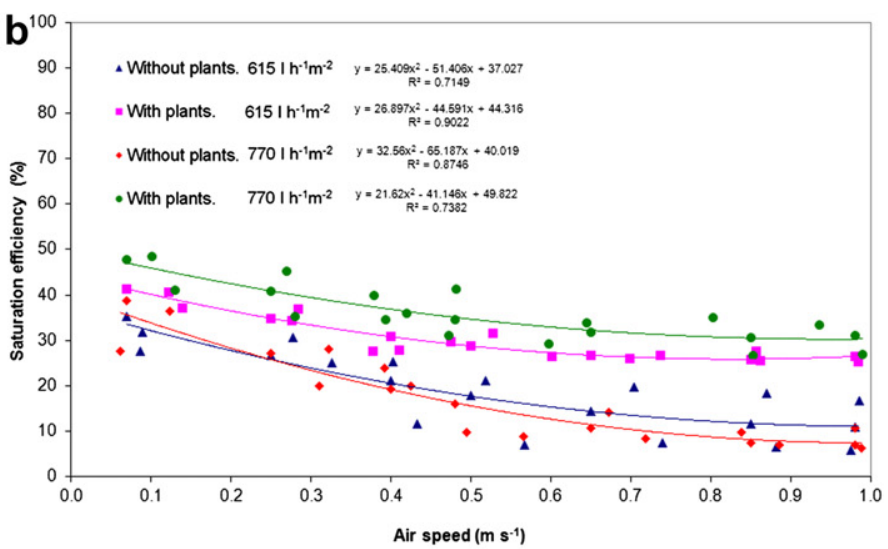



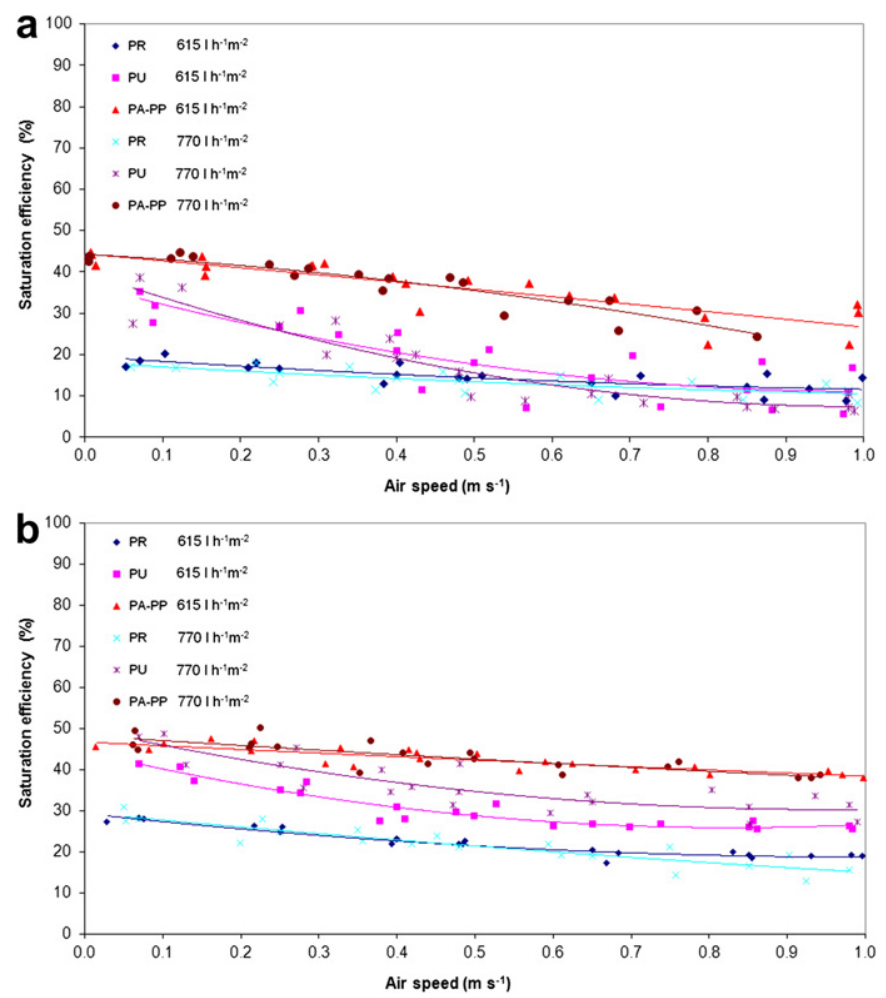

Fig. 9. Saturation efficiency vs. air speed: (a) without vegetation; (b) with vegetation.

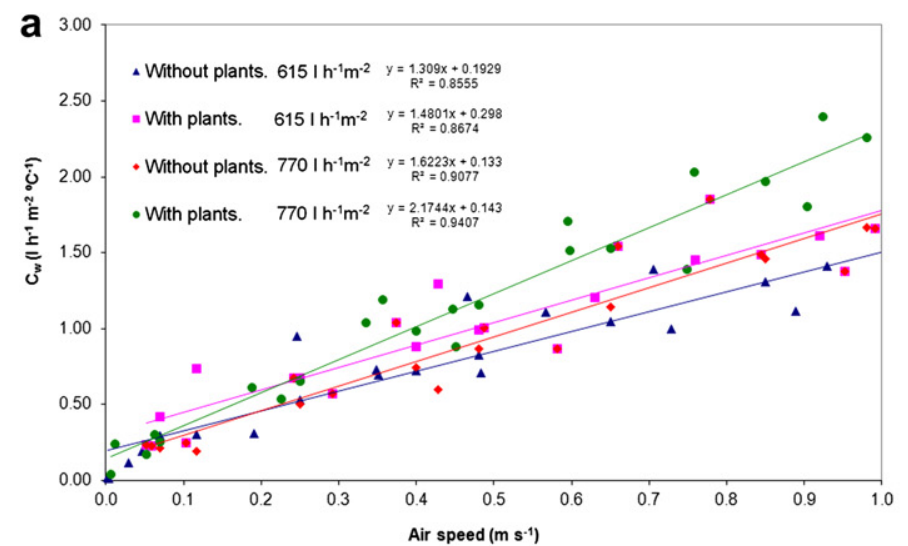

followed by PU which varies between $40.89 \%\left(770 \mathrm{~L} \mathrm{~h}^{-1} \mathrm{~m}^{-2}\right.$ with vegetation) and $7.39 \%\left(770 \mathrm{~L} \mathrm{~h}^{-1} \mathrm{~m}^{-2}\right.$ without vegetation). PR is less efficient: between $25.18 \%$ (770 $\mathrm{L} \mathrm{h}^{-1} \mathrm{~m}^{-2}$ with vegetation) and $11.59 \%$ (615 $\mathrm{L} \mathrm{h}^{-1} \mathrm{~m}^{-2}$ without vegetation). For air speeds over $0.5 \mathrm{~m} \mathrm{~s}^{-1}$, PR is slightly superior to PU.

The high saturation efficiency for PA-PP is related to its high resistance to air flow showed previously. PR retains less water which affects to the contact surface between air and water. Therefore, less water evaporates and the efficiency is lower.

Taking into account the water flows, the results obtained show no differences in air saturation efficiency for PR and PA-PP when the flow of water increases. On the other hand, again due to its higher porosity, the efficiency of PU with vegetation increases by around $17.84 \%$ if the water flow is higher.

The presence of vegetation increases air saturation efficiency in the three substrates because it creates greater resistance to the air flow, resulting in longer contact with water and an increase in evaporation (Fig. 9). The average rise in efficiency due to the presence of vegetation was highest for PU (132.97\%), followed by PR and PA-PP (53.57\% and 26.64\%, respectively).

\subsection{Specific water consumption}

Water consumption is an important parameter due to the shortage of this resource. This value is used to design the irrigation system of the living wall and to choose a suitable pump for water recirculation. The amount of water evaporated by the substrate is related to the air temperature and humidity, the speed of the air flow and the substrate characteristics (thickness, transfer surface, presence of vegetation, etc.).

Fig. 10 shows the specific water consumption for the three types of substrates studied at different air and water flows. It is expressed

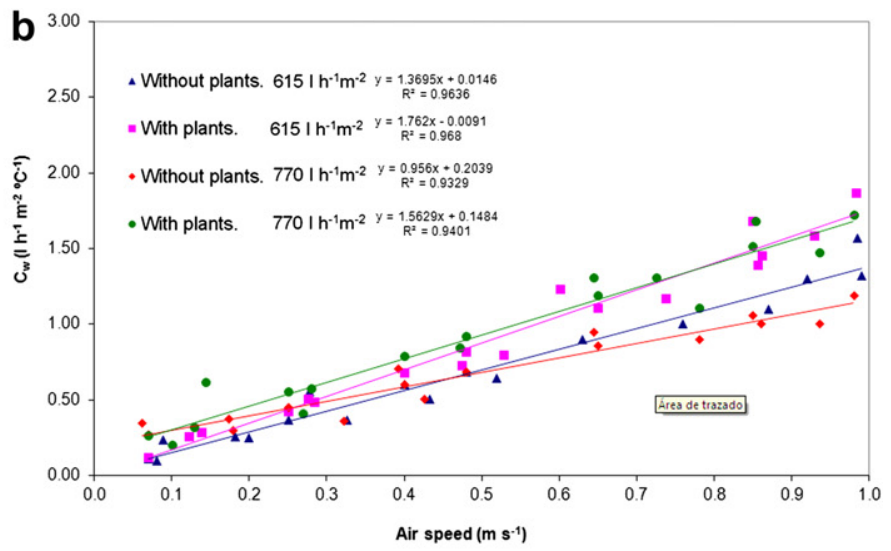

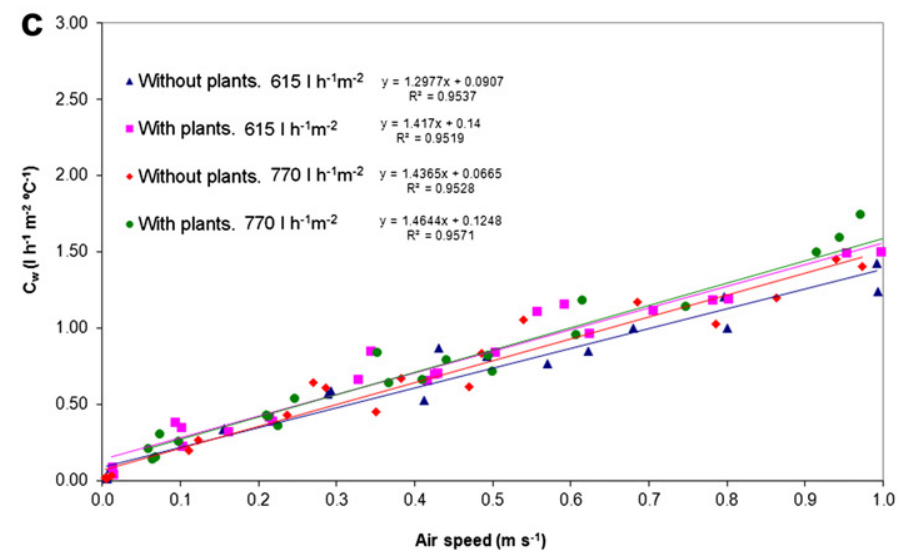

Fig. 10. Water consumption vs. air speed: (a) Polyester (PR); (b) Polyurethane (PU); (c) Polyamide-Polypropylene (PA-PP). 

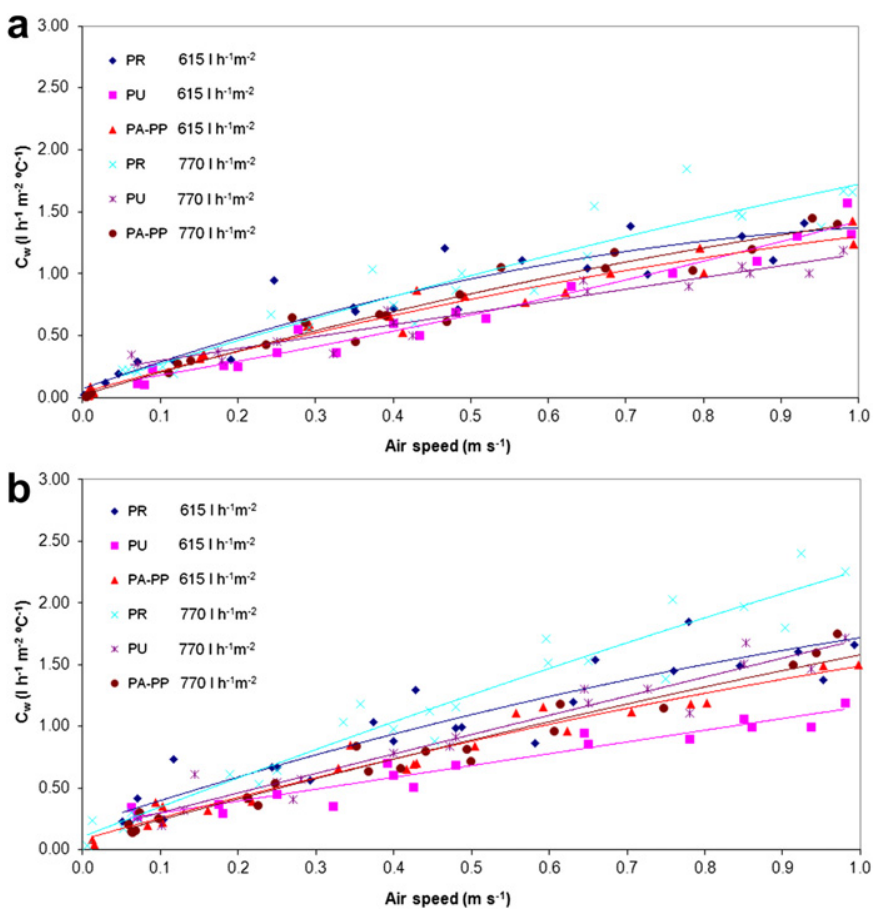

Fig. 11. Water consumption vs. air speed: (a) without vegetation; (b) with vegetation.

as liters of water evaporated per hour per square meter and ${ }^{\circ} \mathrm{C}$ reduction in temperature (Eq. (5)). As the speed of the air flow increases, so does water consumption. For a range of speeds between 0.25 and $1 \mathrm{~m} \mathrm{~s}^{-1}$, average specific water consumption of the three types of substrate without vegetation are 0.45 and $1.45 \mathrm{~L} \mathrm{~h}^{-1} \mathrm{~m}^{-2}{ }^{\circ} \mathrm{C}^{-1}$, respectively. With vegetation, the averages are between 0.55 and $1.79 \mathrm{~L} \mathrm{~h}^{-1} \mathrm{~m}^{-2}{ }^{\circ} \mathrm{C}^{-1}$. This means that water consumption is on average $22.83 \%$ higher due to the presence of vegetation.

Comparison of the substrates reflects minor differences (Fig. 11). PR presents the highest specific water consumption, between $14.4 \%$ and $23 \%$ (without vegetation) and $22.48 \%$ and $51.82 \%$ (with vegetation) greater than PA-PP. Compared to PU, this increase is between $22 \%$ and $42.5 \%$ without vegetation and from $39.6 \%$ to $52.3 \%$ with vegetation.

These results show the relation between specific water consumption and saturation efficiency. In order to evaporate the same amount of water $\left(m_{\mathrm{e}}\right)$, the specific water consumption is lower when the saturation efficiency increases.

\section{Conclusions}

Active living walls are a potent new tool to improve the indoor environment by incorporating nature and vegetation into interiors. However, the design process of these systems is complex and involves a prior study of some of the main elements such as the substrate used for plant development. In this work, three different substrates were tested in order to obtain their operational parameters and their suitability for use in active living walls.

The equipment designed for measurement and data logging and the frame to accommodate the substrates in the wind tunnel, have proved to be suitable for carrying out the tests due to their versatility and ease of use.

A substrate with high water retention foments vegetative growth. The water retained by the substrate without vegetation increases when the water flow is higher. PU retains more water than the others (between 0.77 and $2.05 \mathrm{~L} \mathrm{~m}^{-2}$ ), though the performance of PA-PP is also good. PR presents the worst water retention values $\left(0.34-0.75 \mathrm{~L} \mathrm{~m}^{-2}\right)$.

The resistance to air flow (pressure drop) through the three substrates increases at high air speeds and water flows. High air speeds are not recommended, as they lead to high resistance, damage to vegetation and substrate desiccation and low saturation efficiencies. The recommended range of air speed is between 0.25 and $0.5 \mathrm{~m} \mathrm{~s}^{-1}$. In this range, PA-PP shows the largest pressure drop followed by PR. An air flow of over $770 \mathrm{~L} \mathrm{~h}^{-1} \mathrm{~m}^{-2}$ produces undesirable leaking of water from the substrate, and so ventilators should be chosen carefully in order to provide a correct speed and flow. As for the water flow, it should be enough to saturate the substrate but without increasing the pressure drop in excess.

The air saturation efficiency drops as the speed of the air passing through the substrate increases, and it is slightly affected by the increase in the flow of water. For the correct interval of speeds, PA-PP proved to be the most efficient while PR was the least. Water consumption is also higher when air speed increases.

The presence of vegetation produces greater resistance to the air flow and increases air saturation, though it obviously leads to increased water consumption (22.6\% on average). The average increase in the pressure drop due to the presence of vegetation was highest for PA-PP (58.3\%) and lowest for PU. The average increase in efficiency due to the presence of vegetation was high for PU but lower for PR and PA-PP.

Taking into account all the parameters, PA-PP performs best (high saturation efficiency, average water retention capacity and low water consumption), even though it presents higher drops in pressure. PU offers least resistance and has an average level of efficiency, but its water consumption and water retention capacity are high. PR showed the worst saturation efficiency, average pressure drop and high water consumption.

\section{Acknowledgments}

This work was funded by projects AGL2010-22284-C03-01 of the Ministerio de Ciencia e Innovación of Spain and P09-AGR-4593 of the Junta de Andalucía, and is based upon work supported by OTRI (University of Seville) under the Program for Technology Transfer Activities 2010.

\section{References}

[1] AAE. Estructura del consumo de energía eléctrica por sectores de actividad en 2007. Sevilla, Spain: Agencia Andaluza de la Energía. Consejería de Innovación, Ciencia y Empresa de la Junta de Andalucía; 2007.

[2] IDAE. El Plan de acción de ahorro y eficiencia energética y la rehabilitación energética. Spain: Ministerio de Industria, Turismo y Comercio de España; 2008.

[3] IEA. Energy technology perspectives 2010, scenarios \& strategies to 2050. France: International Energy Agency; 2010.

[4] Smith STh, Hanby VI, Harpham C. A probabilistic analysis of the future potential of evaporative cooling systems in a temperate climate. Energ Build 2011;43:507-16.

[5] Briz J. Naturación Urbana: cubiertas ecológicas y mejora medioambiental. Madrid, Spain: Mundi-Prensa; 2003.

[6] Pérez G, Rincón L, Vila A, González JM, Cabeza LF. Green vertical systems for buildings as passive systems for energy savings. Appl Energy 2011;88(12): 4854-9.

[7] Kontoleon KJ, Eumorfopoulou EA. The effect of the orientation and proportion of a plant-covered wall layer on the thermal performance of a building zone. Build Environ 2010;45:1287-303.

[8] Blanc P. The vertical garden: from nature to the City. W. W. Norton \& Co.; 2008.

[9] Darlington A, Dixon M, Pilger C. The use of biofilters to improve indoor air quality: the removal of toluene, TCE and formaldehyde. Life Support Biosphere Sci 1998;5:63-9.

[10] Perini K, Ottelé M, Fraaij ALA, Haas EM, Raiteri R. Vertical greening systems and the effect on air flow and temperature on the building envelope. Build Environ 2011;46:2287-94. 
[11] Institute of Physics in Berlin-Adlershof. Urban ecological model projects, Berlin Senate for Urban Development. Available in: http://www.a.tu-berlin. de/gte/forschung/Adlershof/\%0afaltblatt_institut_physik_engl.pdf; 2002.

[12] Fernandez-Cañero R, Pérez-Urrestarazu L, Franco A. Assessment of the cooling potential of an indoor living wall using different substrates in a warm climate. Indoor and Built Environ. doi:10.1177/1420326X11420457, in press.

[13] Cheng CY, Cheung K, Chu LM. Thermal performance of a vegetated cladding system on facade walls. Build Environ 2010;45:1779-87.

[14] Schmidt M. The evapotranspiration of greened roofs and façades. In: Fourth annual greening rooftops for sustainable communities, Conference, Boston, USA; 2006.

[15] Currie BA, Bass B. Estimates of air pollution mitigation with green plants and green roofs using the UFORE model. In: Proc. of 3rd north American green roof conference greening rooftops for sustainable communities, Washington, 4-6 May 2005: pp. 495-511.

[16] Tuomainen M, Smolander J, Kurnitski J, Palonen J, Seppanen O. Modelling the cost effects of the indoor environment. In: Proceedings of indoor air, Monterey, California; 2002, pp. 814-819.

[17] Ottelé M, van Bohemen HH, Fraaij AL. Quantifying the deposition of particulate matter on climber vegetation on living walls. Ecol Eng 2010;36(2):154-62.

[18] Dunnett NP, Kingsbury N. Planting green roofs and living walls. Portland: Timber Press; 2004.

[19] Ushada M, Murase H. Design of customisable greening material using swarm modelling. Biosystems Eng 2009;104(2):169-83.

[20] Ip K, Lam M, Miller A. Shading performance of a vertical deciduous climbing plant canopy. Build Environ 2010;45(1):81-8.

[21] Darlington A, Chan M, Malloch D, Pilger C, Dixon MA. The biofiltration of indoor air quality: implications for air indoor air. Indoor Air 2000;10(1):39-46.

[22] Meier K. Strategic landscaping and air-conditioning savings: a literature review. Energ Build 2010;15-16:479-86.

[23] ASHRAE. ASHRAE Handbook-Fundamentals. Atlanta, GA (EEUU): American Society of Heating, Refrigerating and Air-Conditioning; 2009.

[24] Darlington A, Dat JF, Dixon MA. The biofiltration of indoor air: air flux and temperature influences the removal of toluene, ethylbenzene, and xylene. Environ Sci Technol 2001;35:240-6.

[25] Birkeland J. Eco-retrofitting with building integrated living systems. In: Proceedings of the 3rd CIB international conference on smart and sustainable built environment, SASBE09, Delft, Netherlands. 2009.
[26] Valera DL, Álvarez AJ, Molina FD. Aerodynamic analysis of several insect-proof screens used in greenhouses. Span J of Agric Res 2006;4(4):273-9.

[27] Franco A, Valera DL, Madueño A, Peña A. Influence of water and air flow on the performance of cellulose evaporative cooling pads used in mediterranean greenhouses. Trans ASABE 2010;53(2):565-76.

[28] Fang FM, Chen JC, Hong YT. Experimental and analytical evaluation of flow in a square-to-square wind tunnel contraction. J Wind Eng Ind Aerodyn 2001; 89:247-62.

[29] Liao CM, Chiu KH. Wind tunnel modeling the system performance of alternative evaporative cooling pads in Taiwan region. Build Environ 2002;37: 177-87.

[30] Wang Z, Zhang JS. Characterization and performance evaluation of a full-scale activated carbon-based dynamic botanical air filtration system for improving indoor air quality. Build Environ 2011;46:758-68.

[31] Franco A, Valera DL, Peña A, Pérez AM. Aerodynamic analysis and CFD simulation of several cellulose evaporative cooling pads used in Mediterranean greenhouses. Comput Electron Agr 2011;76:218-30.

\section{Nomenclature}

A: surface area of substrate media $\left(\mathrm{m}^{2}\right)$

$C_{p a}$ : specific heat of dry air $\left(\mathrm{kJ} \mathrm{kg}^{-1} \mathrm{~K}^{-1}\right)$

$C_{w}$ : specific water consumption $\left(\mathrm{kg} \mathrm{h}^{-1} \mathrm{~m}^{-2}{ }^{\circ} \mathrm{C}^{-1}\right)$

$m_{a}$ : air mass flow rate $\left(\mathrm{kg} \mathrm{h}^{-1}\right)$

$m_{e}$ : water evaporation rate $\left(\mathrm{kg} \mathrm{h}^{-1}\right)$

$m_{v 1}, m_{v 2}$ : inlet and outlet water vapor flow rate, respectively $\left(\mathrm{kg} \mathrm{h}^{-1}\right)$

$Q_{a}$ : volumetric air flow rate $\left(\mathrm{m}^{3} \mathrm{~h}^{-1}\right)$

$T_{1}, T_{2}$ : inlet and outlet dry-bulb temperature $\left({ }^{\circ} \mathrm{C}\right)$

$T_{w b}$ : thermodynamic wet-bulb temperature of the inlet air

$v$ : air velocity $\left(\mathrm{m} \mathrm{s}^{-1}\right)$

VOC: volatile organic compounds

$W_{1}, W_{2}$ : inlet and outlet humidity ratio, respectively $\left(\mathrm{kg}_{\mathrm{w}} \mathrm{kg}_{\mathrm{a}}^{-1}\right)$

Greek letters

$\eta$ : air saturation efficiency (\%)

$\rho_{a}$ : mass density of air $\left(\mathrm{kg} \mathrm{m}^{-3}\right)$ 